\title{
Subsurface 2D Image Analyses of the Uyangha Basement Area, South-Eastern Nigeria
}

\author{
${ }^{1}$ Peter O. Odong, ${ }^{2}$ Brian E. Usibe, ${ }^{3}$ Vladimir N. Obim \\ ${ }^{12}$ Department of Physics, University of Calabar \\ ${ }^{3}$ Department of Geology, University of Calabar \\ P.M.B. 1115 Calabar, Nigeria
}

\begin{abstract}
Geo-electric soundings were made in Stella Maris Secondary School, in Uyangha, Nigeria to image the subsurface and obtain thicknesses and resistivities of different layers. A quantitative interpretation of the data obtained clearly reveals the presence of four (4) geo-electric sections which are interpreted to be dry laterite, moist laterite, weathered basement, and saturated basement. The depth probed is about $100 \mathrm{~m}$. The saturated basement is the aquifer unit. Depth to aquifer unit in the area is at about $65 \mathrm{~m}$ to $80 \mathrm{~m}$. The thickness of the aquifer unit ranges from $20 \mathrm{~m}$ to $35 \mathrm{~m}$. For ground water exploitation, boreholes in the area should therefore be drilled to the depth of $91 \mathrm{~m}$, for reasonable groundwater yield. The lateritic layer makes the study area suitable for building construction in the area.
\end{abstract}

Keywords: 2-D imaging, electrical resistivity, vertical electrical sounding, pseudo-section, saturated basement.

\section{Introduction}

Geophysical surveys are aimed at detecting and locating subsurface geological structures and to measure their dimensions and their physical properties. Geophysical exploration methods are many, which can be classed according to the source of energy used in their measurement.

To select a suitable method to be used for any survey, a comprehensive knowledge of the geology of the area and site conditions are necessary. This is because in some instances, site conditions may preclude the successful use of most if not all geophysical techniques. The resistivity study requires the introduction of an artificial current into the ground through point electrodes or long line contacts. The potential in the earth (ground) due to the introduction of the current into the ground is measured using two potential electrodes which are planted on the ground surface. Since the current is measured as well, it is possible to determine the apparent resistivity of the subsurface. This however makes the resistivity method more superior (at least theoretically) to all the other electrical methods (Keary and Brooks 1991). It is important to note that, deviations from the pattern of potential differences expected from homogenous medium, provides information on the form and electrical properties of subsurface inhomogenities. The depth soundings or a vertical electrical sounding (VES) is also known as electrical drilling. It is the process by which depth investigations are made (Zohdy, et al., 1974).

The technique is best adopted to determining depth and resistivity for flat laying layered rock such as found in sedimentary terrains. The Schlumberger configuration is mostly commonly used for VES investigations.

The technique further finds application in geotechnical survey to determine overburden thickness and also in hydrogeology, to define depth and thickness of porous strata which are potential aquifers (Burger, 1992).

The objectives of the study are to attempt to identify the different rock types in the area and their vertical thickness using the electrical resistivity method.

This result will help to detect saturated layers for ground water exploitation in the area.

The apparent resistivity of the ground is a function of the measured impedance (ratio of potential to current) and the geometry of the electrode array (Burger, 1992).

\section{Geologic Setting}

The study area is a basement terrain with an over burden. It is however a part of Oban Massif. The Oban Massif is located in the Southeastern region of Nigeria consisting of Precambrian basement complex, overlain by cretaceous to tertiary sediments of the Calabar flank. The Oban massif is in Southeastern Nigeria and includes mappable metamorphic rock units such as phyllites, schist, gneisses and amphibolites. The rocks are believed to have been intruded by pegmatites, granites, granodiorites. Outcrops of rocks in the area show that the rocks are intensively weathered which makes it difficult to obtain fresh rocks for geological identification (Ekwueme et al, 1995).

In Uyanga, the granodiorites enclose unmappable xenolith of meladiorite. This can be observed along the Calabar - Ikom road. The meladiorite is dark and fine - grained. The margin is basified; it is comprised dominantly of plagioclase, hornblende, minor quartz and biotite (Ekwueme et al, 1995). 


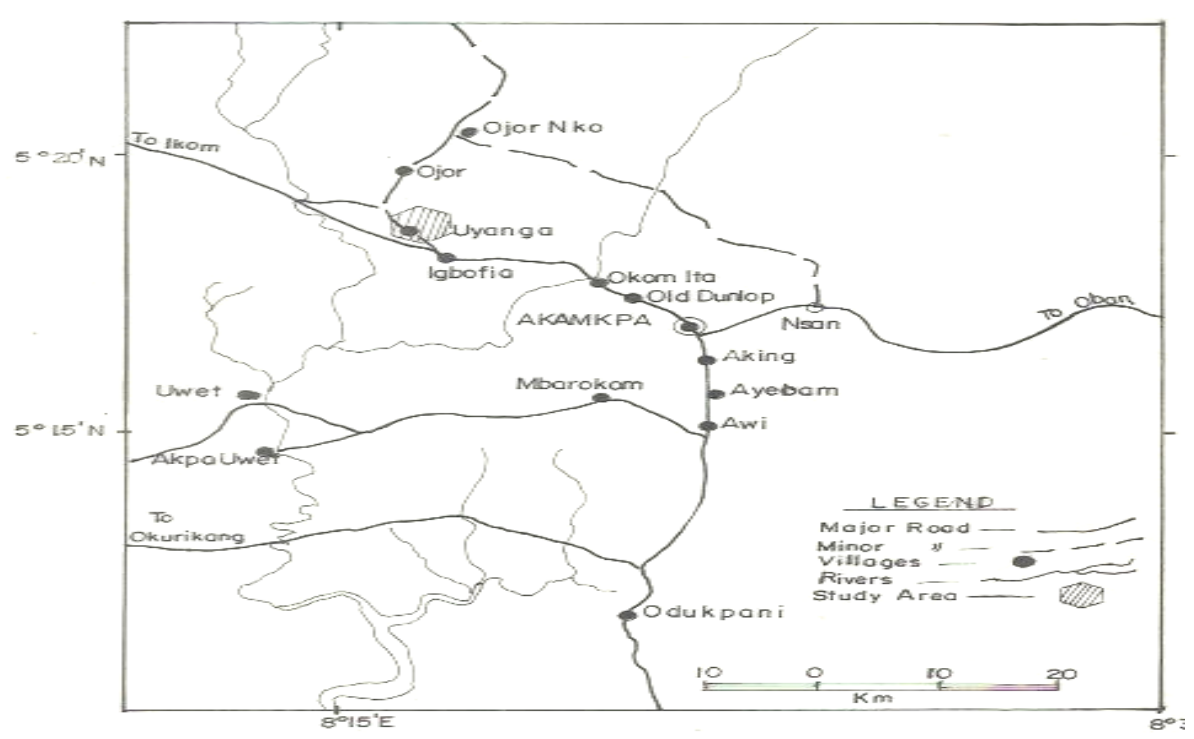

Figure 1: Location map of the study area.

The study area is located at the Stella Maris Seminary, Uyanga in the Akamkpa Local Government Area of Cross River State, Nigeria.

\section{Materials And Method}

The instrument used to measure data is an ABEM TERRAMETER model SAS 300B.

A booster control unit is also incorporated in the terrameter to help drive large current into the ground in cases where a more resistive terrain is involved, other materials used are, the Global Positioning system, four electrodes, measuring tapes, hammers and cables. The electrode arrangement used in data acquisition is the Schlumberger array of electrodes.

\section{Results}

The observed field data was converted to apparent resistivity by multiplying with the Schlumberger geometric factor. The geometric factor for the Schlumberger array is given by:

Where $\mathrm{L}=$ half current electrode spacing,

$$
G=\frac{\pi}{2 l}\left(L^{2}-l^{2}\right)
$$

$1=$ half potential electrode spacing

The apparent resistivity data were plotted against the half current electrode spacing in meters in the horizontal axis. The resistivity data were further interpreted using IPI2Win inversion software package (Bobachev, 2002).

The curves resulting from the plots are given below:

(a)

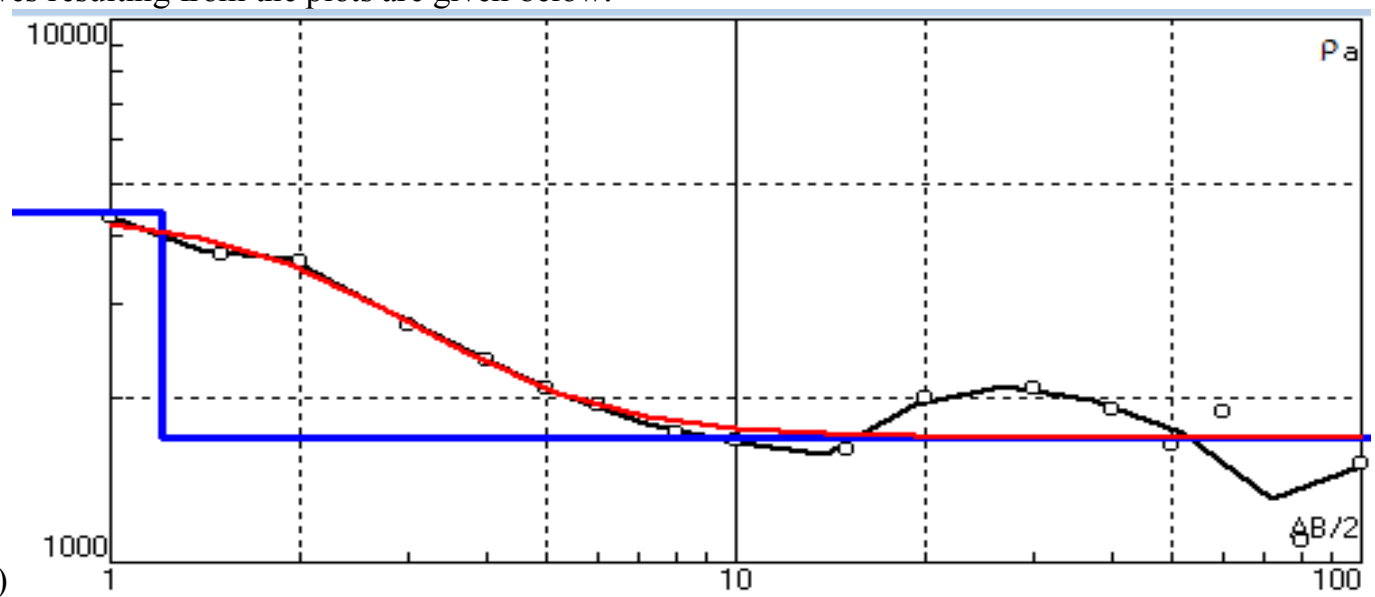




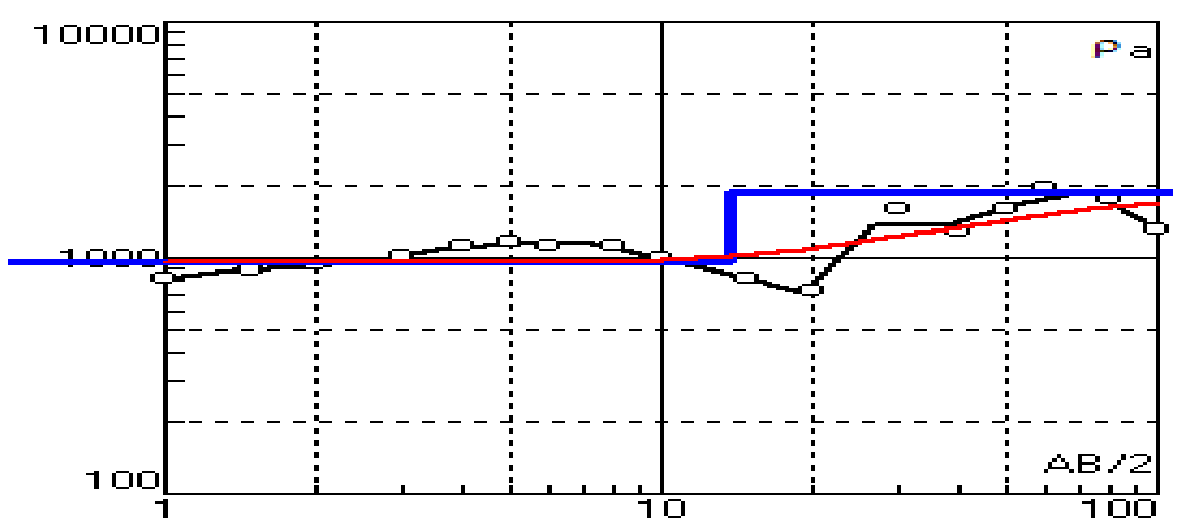

(b)

Figure 2: VES curves (a) and (b) representing plots for VES (1) and (2) respectively

The data obtained in VES 1 and VES 2 were analyzed using computer modeling technique. The output results obtained from the computer are shown above in Fig: 2a and Fig $2 b$.

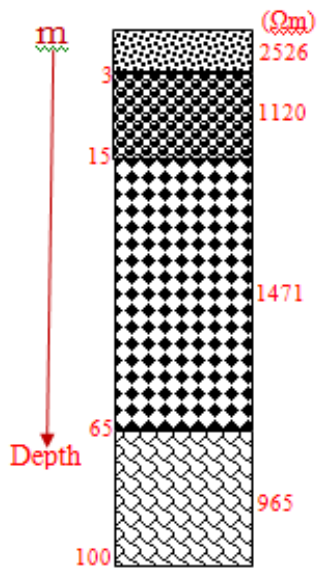

(a)

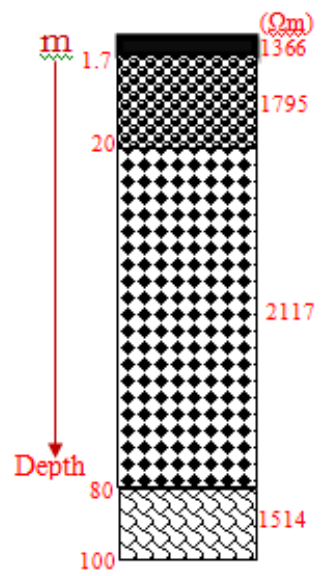

(b)

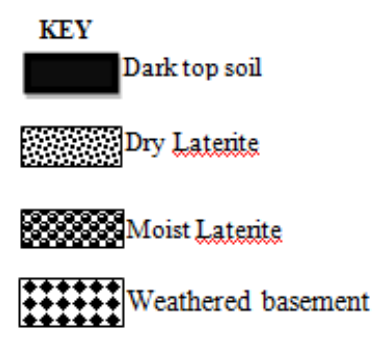

Saturated basement

Figure 3: Geo-electric and inferred geologic sections for VES 1 and VES 2 respectively
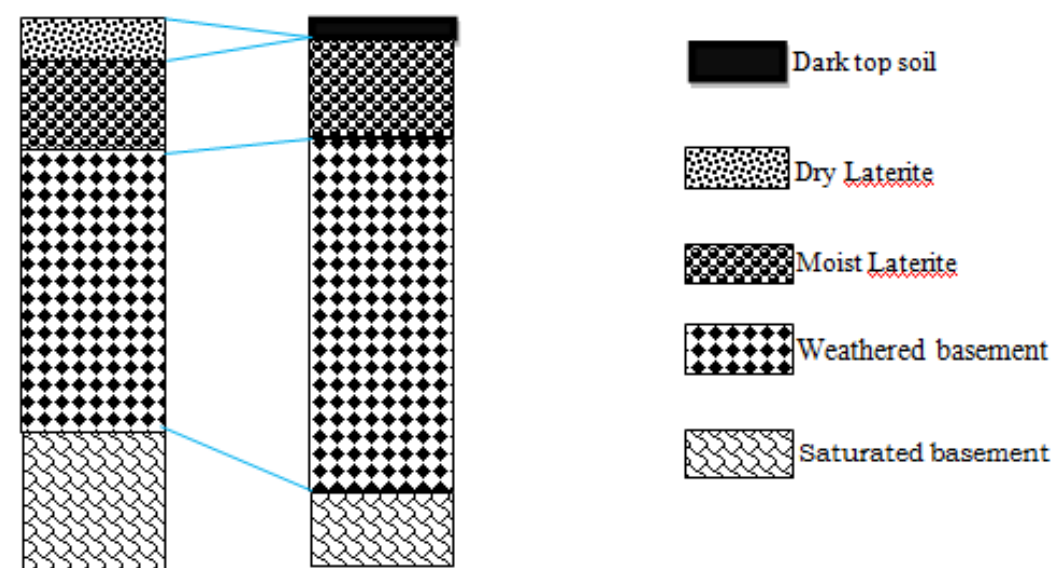

Figure 4: Correlation of inferredlithologic units of VES 1 and VES 2

It is observed from the above correlation that the dry lateritic layer evident in VES 1 did not appear in VES 2 which is covered with a relatively thin dark top soil layer. Thus in VES 1 the dark top soil has been washed by erosion over time. The weathered basement layer in VES 2 is thicker than that of VES 1. The results of parameters integrated from the geo-electric sections in the study area is presented in table 1 below. A pseudosection, which is an attempt to present the appearance of the subsurface of the study area is given below in Fig.5 
Table 1: Results of parameters integrated from the geo-electric sections in the study area

\begin{tabular}{|l|ccccc|}
\hline VES NO. 1 & Layers & Depth $(\mathrm{m})$ & Thickness $(\mathrm{m})$ & Resistivity $(\Omega \mathrm{m})$ & Rock type \\
\cline { 2 - 6 } & 1 & 3 & 3 & 2526 & Dry Laterite \\
\cline { 2 - 6 } & 2 & 15 & 12 & 1120 & Moist Laterite \\
\cline { 2 - 6 } & 3 & 65 & 50 & 1471 & Weathered basement \\
\cline { 2 - 6 } & 4 & 100 & 35 & 965 & Saturated basement \\
\hline VES NO. 2 & 1 & 1.7 & 1.7 & 1366 & Moist Laterite \\
\cline { 2 - 6 } & 2 & 20 & 18.3 & 1795 & Weathered basement \\
\cline { 2 - 6 } & 3 & 80 & 60 & 2117 & Saturated basement \\
\cline { 2 - 5 } & 4 & 100 & 20 & 1514 &
\end{tabular}

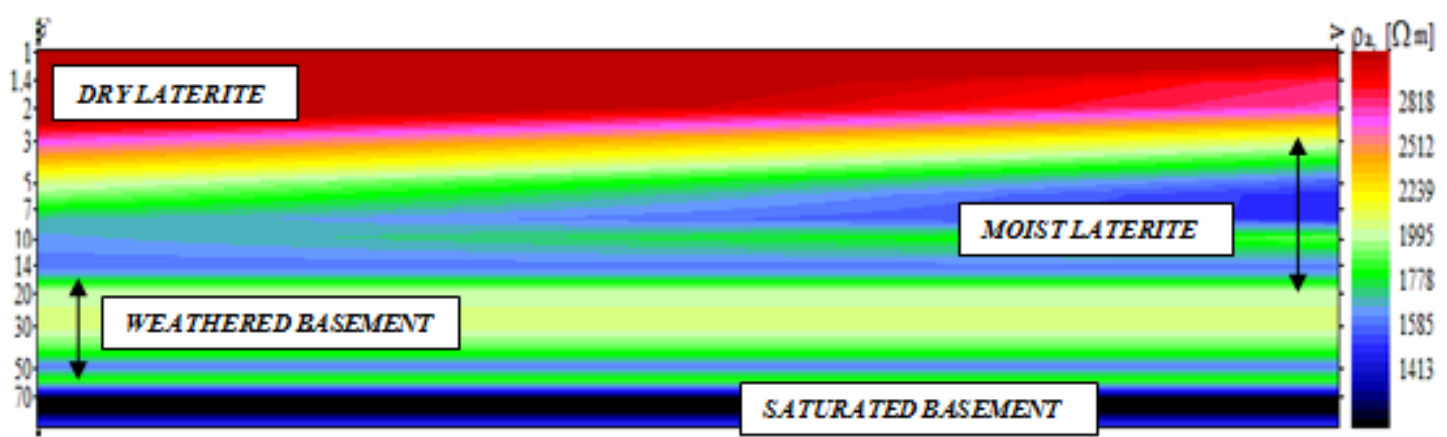

Figure 5: A pseudo-section of the study area.

\section{Conclusion}

The result gives a 2D image of the subsurface, showing internal and vertical variations in resistivities. A quantitative interpretation of the data obtained clearly shows four layers in the geoelectric section which are interpreted to be dry laterite, moist laterite, weathered basement and saturated basement. Hence, the method adopted in the investigation of the study area has helped in the identification of aquifer unit. The groundwater can be exploited for the benefit of the Stella Maris students and residence of Uyangha, Akamkpa in Nigeria. Borehole in the area should be drilled to at least 91meters. The site is also suitable for classrooms construction.

\section{References}

[1] Alabi, A. A., Bello, R., Ogungbe A.S., Oyerinde, H. O, 2010,: Determination of Groundwater Potential in Lagos State University, Ojo: Using Geoelectric Methods (Vertical Electrical Sounding and Horizontal Profilling), Rep. Opin., 2(5): pp 68-75

[2] Alile, O. M, Ujuambi., and Evbuomwan, I.A, 2011,: Geoelectric Investigation of Groundwater in Obaretin- Iyanornon Locality, Edo State, Nigeria, Journal of Geology and Mining Research Vol.3 (1) pp. 13-20,

[3] Bobachev, A., 2002,: IPI2win- A Window Software of an Automatic Interpretation of Resistivity Sounding Data; Moscow State University, pp. 320

[4] Benson O. (1982): Field sampling Procedures; Chicago, Neally Limited. Manual PP 5-9

[5] Burger H. R(1992): Exploration Geophysics of the Shallow subsurface practice Hall, Inc. PP 80-82

[6] Ekwueme, B. N. Nyong E. E and Peters S. W. (1995): Geological excursion guidebook to Oban Massif, Calabar flank and Mamfe embayment, Southeastern Nigeria. $1^{\text {st }}$ ed. Decford Publishers Ltd. PP 6-8

[7] Keary, P. and Brooks, M. (1991): An introduction to geophysical Exploration. $2^{\text {nd }}$ ed. London; Cambridge University Press. Pp.173184

[8] Lowrie, W(1997): Fundamentals of geophysics; $1^{\text {st }}$ ed York; Cambridge University Press. Pp 150-200

[9] Telford, W. M., Geldart, L. P and Sheriff, R. E. (1991): Applied geophysics $2^{\text {nd }}$ ed;

[10] Umanah, M. E. (2006): Interpretation of Electrical Sounding Data from a Basement Terrain. (Uyanga in Akamkpa Local Government Area of Cross River State - Nigeria).

[11] Zohdy, A. R., Eaton, G. P. and Mabey, D. R., (1974): Application of Surface Geophysics to Groundwater Investigations: Techniques of Water-Resources Investigations of U.S. Geological Survey, Chapter D1, Book 2, pp 116 